\title{
FRACTURES CAUSED BY CHILD ABUSE
}

\author{
HELEN M. L. CARTY
}

From the Royal Liverpool Children's NHS Trust, Alder Hey, Liverpool, England

Caffey's paper on the association between fractures of the long bones and subdural haematoma, published in 1946, was the first modern description of the consequences of child abuse, now often referred to by the euphemism 'non-accidental injury'. Since then there have been many reports of the skeletal injuries in the radiological and paediatric literature (Caffey 1957; Kempe et al 1962; Griffiths and Moynihan 1963; Silverman 1972; Merten, Radkowski and Leonidas 1983; Ellerstein and Norris 1984; Chapman 1990; Kleinman 1990), papers describing their pathological and radiological features (Kleinman, Marks and Blackbourne 1986; Kleinman et al 1991), and articles contrasting the patterns of fractures caused accidentally and nonaccidentally (Anderson 1982; Beals and Tufts 1983; Worlock, Stower and Barbor 1986; King et al 1988; Loder and Bookout 1991; Thomas et al 1991). These aspects of the musculoskeletal injuries of non-accidental injury will be reviewed.

\section{INCIDENCE}

The fractures of child abuse occur most frequently in infants under three years old (Ebbin et al 1969; Herndon 1983). Akbarnia et al (1974) reported that $50 \%$ were in children less than one year old and $78 \%$ in children under three. Kogutt, Swischuk and Fagan (1974) found that $55 \%$ of all such fractures were in children under one year old. By contrast, accidental fractures are comparatively rare in children under one year (Worlock et al 1986).

\section{SPECIFICITY}

The fractures caused by child abuse which are widely thought to have a high specificity are listed in Table I, and those which occur frequently but have a low specificity in Table II. Some features of fractures with a low specificity such as diaphyseal lesions, which increase their significance, are given in Table III. Unless they

H. M. L. Carty, FRCPI, FRCR, Consultant Radiologist and Clinical Director of Radiology

Department of Radiology, Royal Liverpool Children's NHS Trust, Alder Hey, Eaton Road, Liverpool L12 2AP, UK.

(C)1993 British Editorial Society of Bone and Joint Surgery

$0301-620 X / 93 / 6682 \$ 2.00$

J Bone Joint Surg [ Br] 1993; 75-B :849-57. present when they are already healing, fractures of the diaphyses look no different from those sustained accidentally; the presenting history has therefore to be carefully evaluated. In the case of an isolated fracture of a long bone, it is the absence of an appropriate history that should alert the clinician to the possibility of abuse (Beals and Tufts 1983; Thomas et al 1991). Delay in seeking medical care is another important feature in the history and further evidence, such as a torn frenulum of the lips or bruising elsewhere on the body, needs to be specifically sought. If there is bruising of a limb that is to be covered by a plaster or splint, it should be photographed before treatment begins.

\begin{tabular}{l} 
Table I. Fractures considered to have a \\
high specificity for child abuse \\
\hline Metaphyseal fractures \\
Rib fractures \\
Scapular fractures \\
Fractures of the outer end of the clavicle \\
Vertebral fractures or subluxations \\
Finger injuries in non-ambulant children \\
Fractures of different ages \\
Bilateral fractures \\
Complex skull fractures
\end{tabular}

Table II. Fractures which are frequent but have a low specificity for child abuse

Mid-clavicular fractures

Simple linear skull fractures

Single diaphyseal fractures

Table III. Features that increase the significance of a diaphyseal fracture

Association with another fracture or other clinical features with a high specificity for abuse

Inappropriate clinical history

Failure to seek medical attention

Discovery of the fracture in a healing state 


\section{FRACTURE PATTERNS}

Metaphyseal fractures of the long bones, although they are known to be specific for child abuse, are much less common than diaphyseal fractures. Merten et al (1983) reported that the incidence of diaphyseal fractures was four times that of metaphyseal fractures. Loder and Bookout (1991) found that metaphyseal fractures accounted for $28 \%$ of non-accidental long-bone injuries whereas Kogutt et al (1974) found the incidence to be $15 \%$ and Worlock et al (1986) $11 \%$. Coexistence of two or more fractures has been reported in 23\% (Kogutt et al 1974), 50\% (King et al 1988), 74\% (Worlock et al 1986), $54 \%$ (Merten et al 1983), and 27\% (Loder and Bookout 1991) of abused infants. The most frequently injured long bones are the femur, humerus and tibia (Kogutt et al 1974 ; King et al 1988).

It is often stated that spiral fractures, which imply a twisting force, should cause suspicion of child abuse. Several reviews have addressed the issue of the significance of fracture types (Figs 1 and 2), and their conclusions can be summarised. With the exception of supracondylar fractures, all fractures of the humerus in children under the age of three are strongly suggestive of abuse (Merten et al 1983; Worlock et al 1986; Thomas et al 1991). Supracondylar fractures do occur non-accidentally (Fig. 2) (Worlock et al 1986), but once children have begun to walk they can also happen accidentally, and their significance is less (Thomas et al 1991). Femoral fractures occurring under the age of one year are more often than not due to abuse (Beals and Tufts 1983; Thomas et al 1991). Anderson (1982) reported that 19 of 24 children under the age of two with femoral shaft fractures had been abused.

\section{Fig. 1}

A recent transverse fracture of the mid-shaft of the humerus with a periosteal reaction along the diaphysis, indicating a previous injury. There is also periosteal reaction around the radius and ulna. The child also had multiple rib fractures (see Fig. 10).

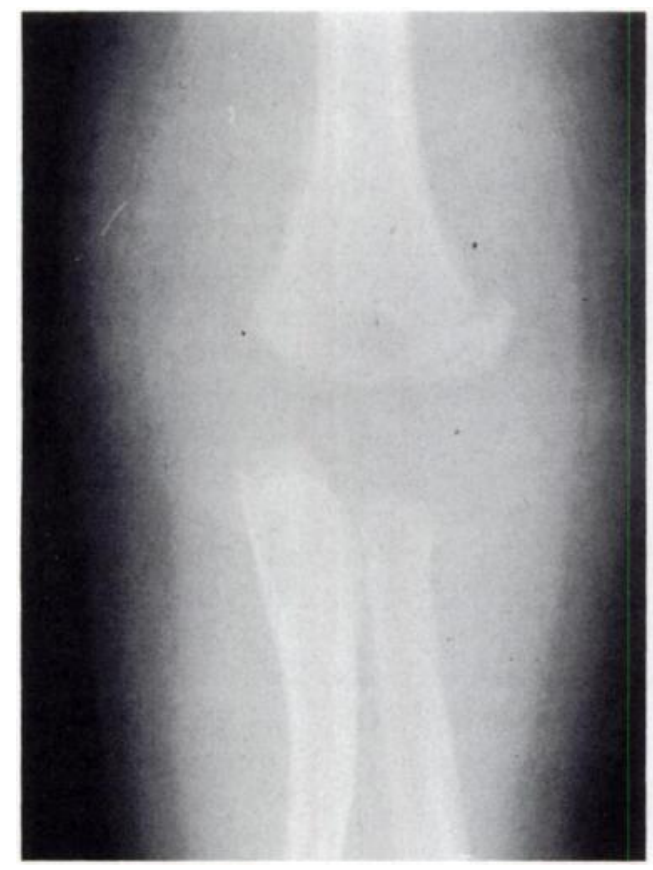

Fig. 2a

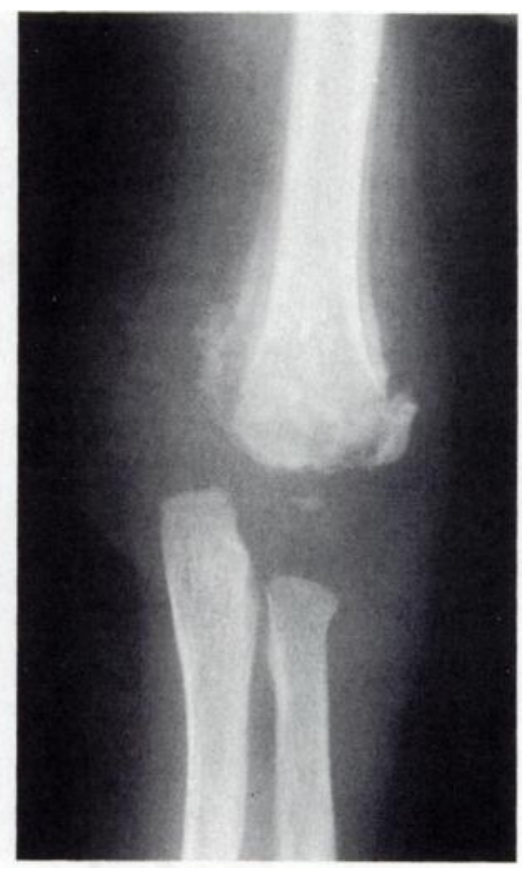

Fig. $2 b$

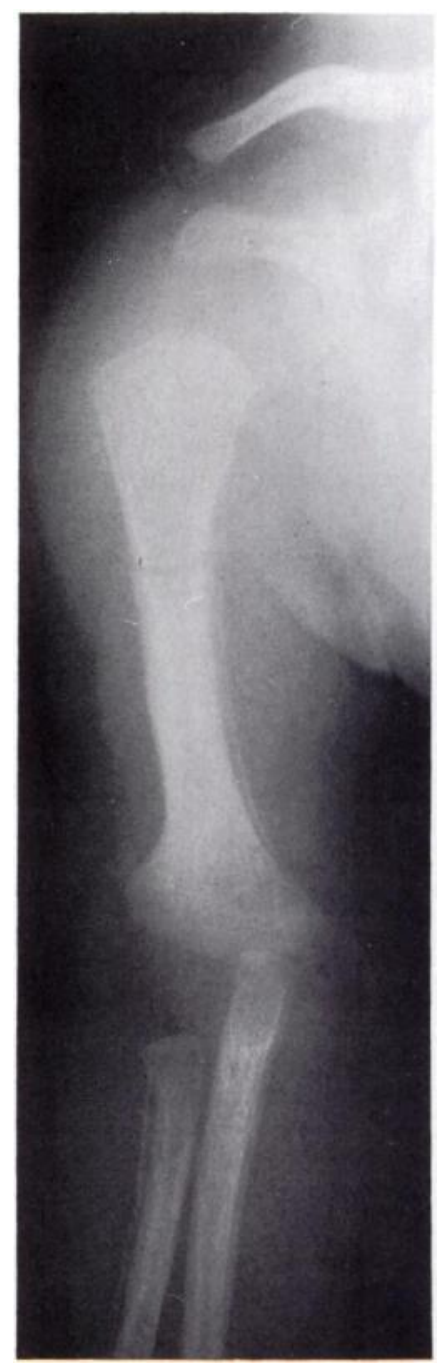

Radiographs of a child whose father ultimately admitted snatching up the child by its arm. On presentation the child had an inflamed and swollen elbow. The first radiograph (a) showed soft-tissue oedema, blurring of the fat planes and a healing supracondylar fracture with periosteal new bone. There is also subluxation of the ulna. Four days later (b) the ulnar subluxation was more obvious and the periosteal reaction was of two different ages. 
Statements such as "It must have occurred when I changed his nappy", or "I found him in his cot like this. He must have caught his leg in the bars", or "I don't know how it happened" are not adequate explanations for fractured femora in normal children. Young children starting to walk may sustain femoral fractures including spiral fractures of the shaft from falls (Thomas et al 1991) but the history needs to be carefully scrutinised in each case before accepting that the injury was accidental. Several types of fracture of the long bones seen in cases of child abuse result from the use of the limbs as handles to snatch the child from where it has been lying.

Beyond the toddling age children can relate their history. They may sustain non-accidental oblique or spiral fractures of a tibia indirectly if an adult hand grabs and twists the limb.

Metaphyseal lesions. The metaphyseal fractures of child abuse are usually very close to the growth plate, unlike accidental metaphyseal fractures which are usually at the junction of the diaphysis and metaphysis and are of the torus variety (Fig. 3). The metaphyseal fractures of abuse occur through the most immature part of the metaphyseal bone (Kleinman et al 1986) and an ossified fragment or ring of metaphysis is avulsed with the physis and may appear as a 'bucket-handle' or 'corner' fracture (Figs 4 and 5). The fracture may be visible in only one radiographic projection. These fractures are transmetaphyseal and are not simply avulsions of the periphery of the metaphysis (Kleinman 1990) as was originally thought. Depending on the extent of subperiosteal bleeding, fracture repair may be accompanied by subperiosteal new bone formation, but this is not

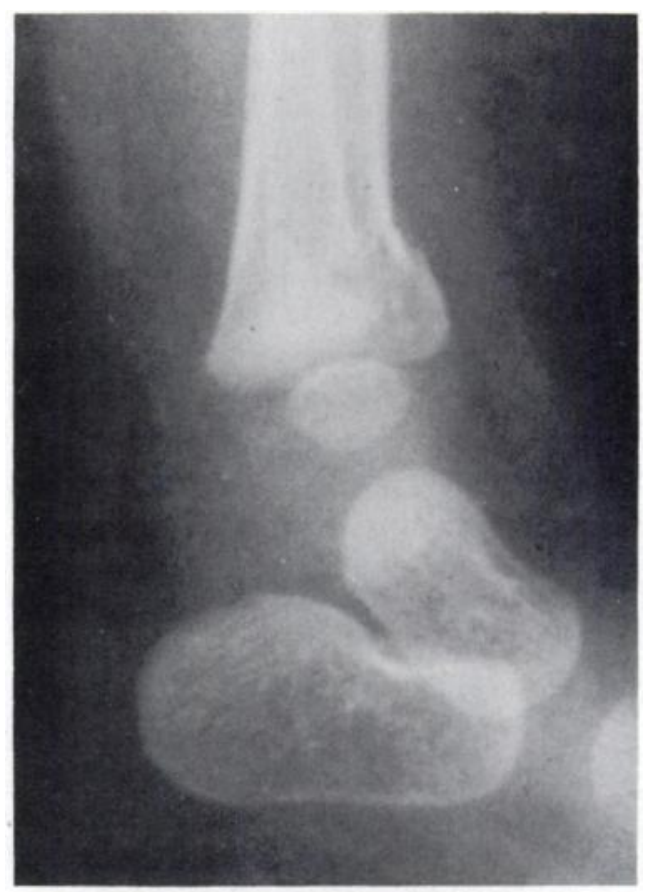

Fig. 3

An accidental metaphyseal fracture in a toddler. The fracture is not at the 'corner' but at the junction between the diaphysis and the metaphysis.

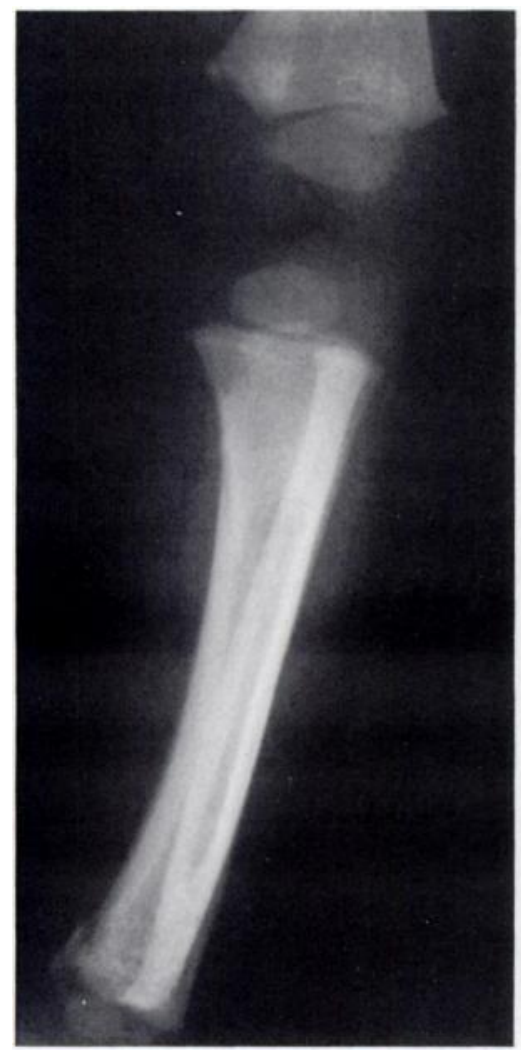

Fig. 4

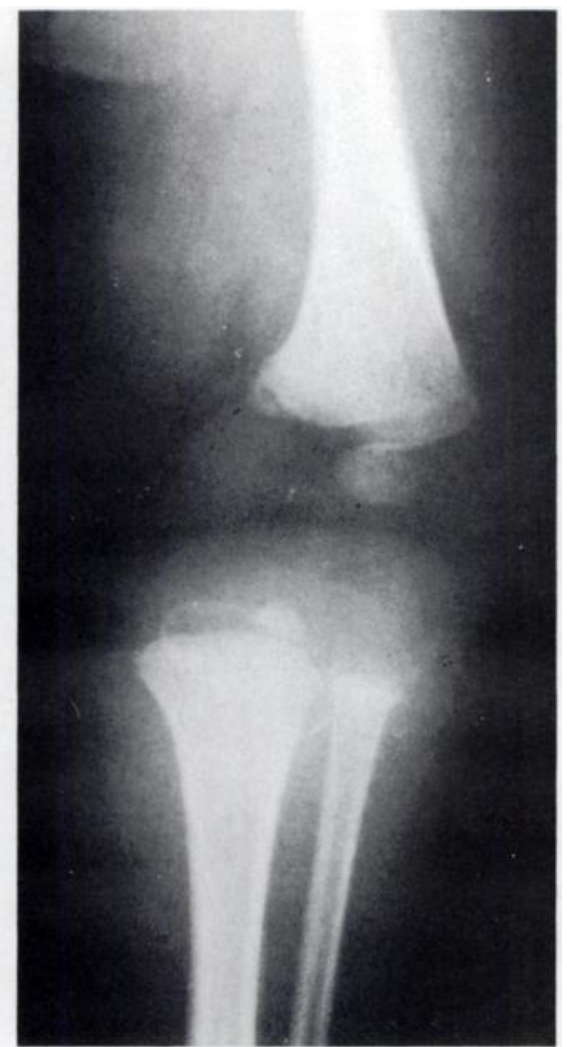

Fig. 5
Figure 4 - There is a corner fracture of the medial femoral metaphysis and a buckethandle fracture of the distal tibia. The femoral fracture healed without periosteal reaction. Figure 5 - A bucket-handle metaphyseal fracture of the proximal tibia with tibial subluxation and a corner fracture of the medial femoral metaphysis. 
invariable (Kleinman et al 1986). It is not true, as sometimes stated, that the lesion cannot be a fracture if no new bone has formed. Repair may appear simply as a thickening of the cortex or squaring of the edges of the metaphysis (Kleinman et al 1986; Figs 6 and 7). The periosteal haematoma when present may extend a considerable distance from the fracture along the diaphysis (Fig. $7 b$ ), producing a much more extensive periosteal reaction than an accidental metaphyseal torus fracture. Periosteal new bone may cloak the whole bone and even suggest a metabolic bone disease or dysplasia (Fig. 8). This generally indicates repeated trauma as also do breaks in the outer layer of the periosteal new bone.

The significance of metaphyseal fractures is that they are often caused by a shaking injury which can also inflict serious brain damage. The author has seen several medical reports in which such fractures were misleadingly described as 'trivial'. The metaphyseal injuries usually heal without long-term consequences, and in that sense are not important, but they must be regarded as sinister because of their associations.

A variant of metaphyseal injury which is not so well known is shown by a radiographic translucency in the immediate subphyseal region (Fig. 9), similar to that sometimes seen in chronic illness such as leukaemia. In leukaemia, the lesions are symmetrical, and there is other evidence of the underlying disorder. That these translucencies are true metaphyseal fractures has been conclusively shown by histopathological studies (Kleinman et al 1986, 1991); their significance must not be overlooked.

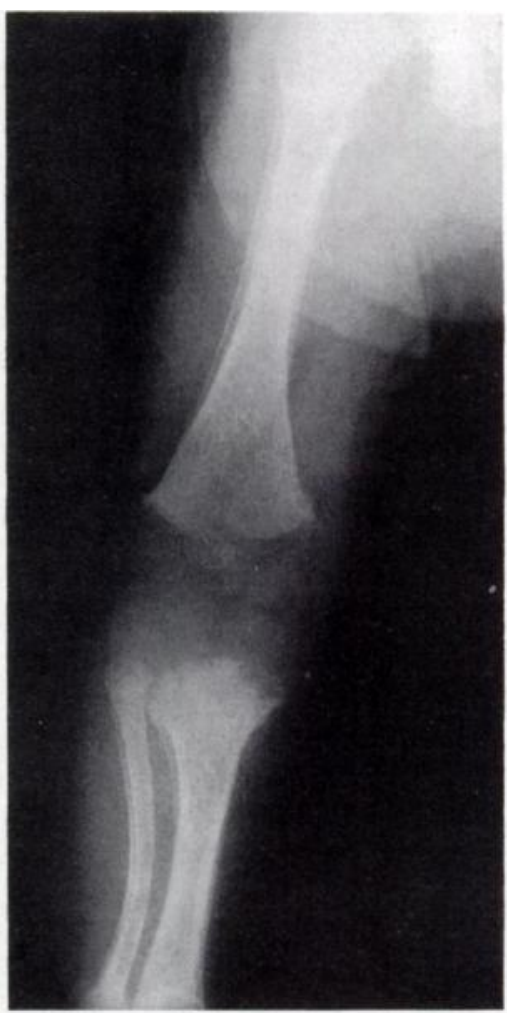

Fig. 6

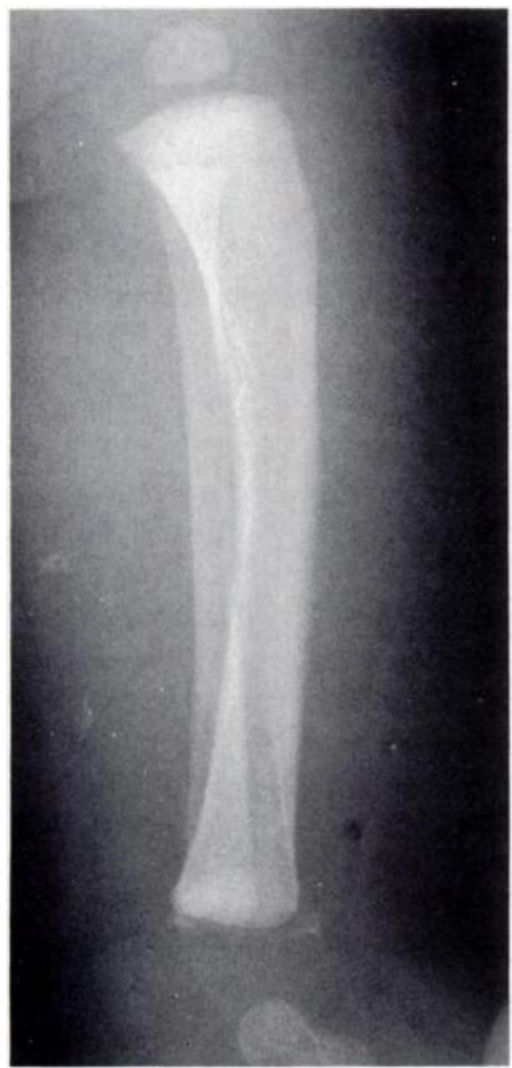

Fig. 7a

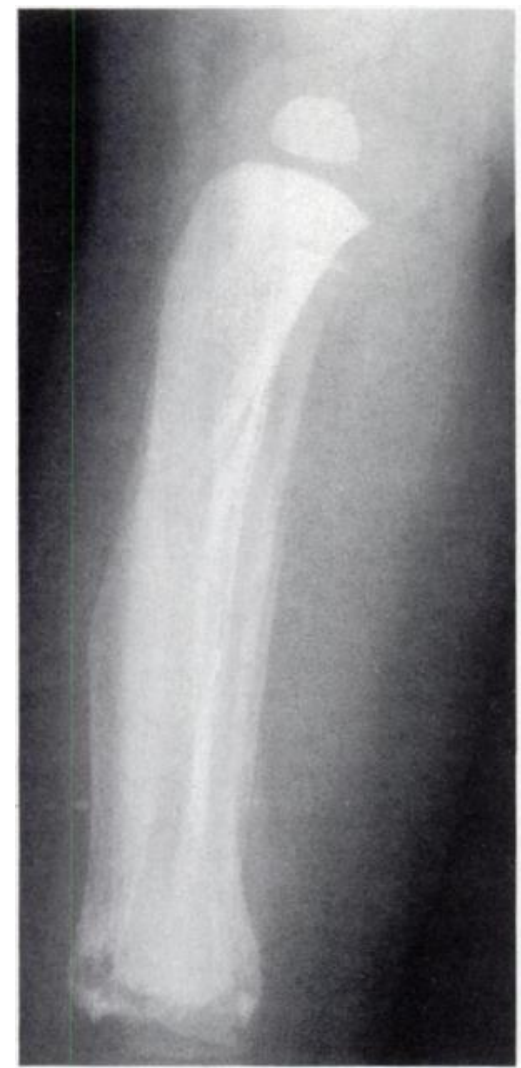

Fig. $7 b$
Healing metaphyseal fracture of the distal femur without local periosteal reaction. The diaphyseal periosteal reactions around the femur, tibia and fibula are traumatic. There is also a healing metaphyseal fracture of the proximal tibia (same child as in Figs 1 and 10).
The radiograph on admission (a) shows an avulsed fragment of the distal tibial metaphysis. Three-and-a-half weeks later (b) the radiograph shows the squared off lower end of the bone and gross subperiosteal haematoma which is now ossified. 


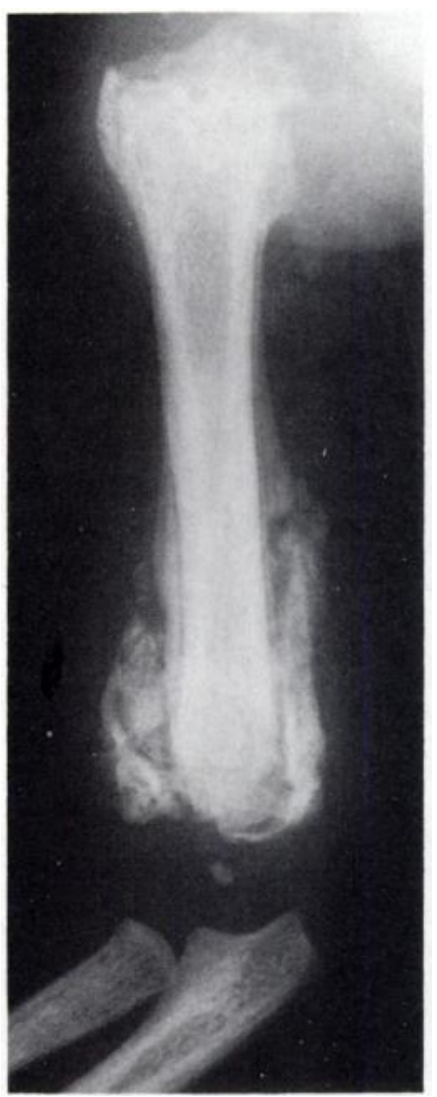

Fig. 8

The humerus shows gross periosteal reaction of several different ages. There is also a fracture through the new bone medially. This child was at first thought to have osteomyelitis since on presentation she had a hot, swollen upper arm.

Metaphyseal fractures most commonly affect the tibia, femur and proximal humerus (Kleinman 1990). They may be bilateral and symmetrical but they may also be isolated. They can occur from indirectly applied acceleration and deceleration forces during shaking or forceful pulling or twisting of an infant's limb (Kleinman 1990). Symmetrical fractures are usually caused by shaking and isolated lesions and are more likely to occur by direct force.

There are some normal metaphyseal variations which may be mistaken for evidence of abuse. The two most common are small beaks or spurs adjacent to the growth plate, which may look like corner fractures (Kleinman et al 1991). These spurs, however, are in continuity with normal bone and with the cortex.

Metaphyseal fractures, even when recent, are frequently undetectable clinically by experienced clinicians. They do not apparently cause pain, except when they are severe or accompanied by epiphyseal displacement. The only evidence that they exist is radiological, hence the need for the skeletal survey.

Repeated or severe injury with extensive subperiosteal bleeding may present clinically as a warm swollen

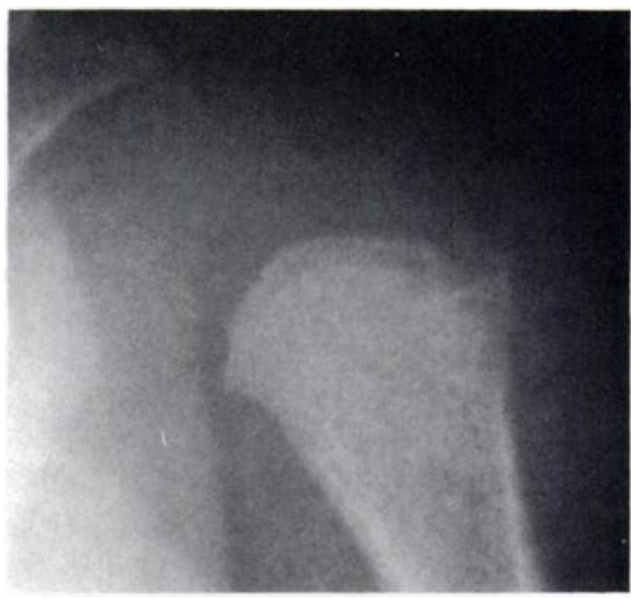

Fig. 9

There is a healed metaphyseal corner fracture laterally. The lucent line in the subphyseal area represents a further metaphyseal fracture.

limb and give rise to a suspicion of osteomyelitis, the bizarre appearance on the radiographs often adding to the confusion (Fig. 8). Acute osteomyelitis is not, however, accompanied by any changes on the radiograph. Chronic osteomyelitis usually causes changes in the shaft and in the central part of the metaphysis, not at the corner as in abuse, and in current practice it is seldom, if ever, the presenting episode.

Periosteal new bone. Periosteal reaction in child abuse is most commonly due to fracture repair but may also be seen without a fracture. Caffey (1946) postulated that periosteal damage occurred from rough gripping of the limbs but it has now been shown that the lesions can result from shaking alone, when acceleration and deceleration forces are applied to the unsupported limbs (Kleinman 1987a; Chapman 1990). Areas of increased radionucleide uptake may be seen at sites of subperiosteal haemorrhage even when the radiographs are normal (Sty and Starshak 1983).

Periosteal new bone formation is sometimes seen as a normal variation in infants aged from six weeks to six months. In child abuse, however, the periosteal reaction often extends to the metaphysis while in the physiological form the new bone is always smooth, lamellar, confined to the diaphysis and usually most obvious on the medial aspect of the shaft of the bone. The most commonly involved bone is the femur, but this may also be seen in the humerus and the tibia.

Epiphyseal injuries. True Salter-Harris epiphyseal plate injuries may occur from child abuse but are relatively rare. Fracture separation of the epiphyses and dislocations are sometimes seen and may be detected by ultrasonography before they become radiographically demonstrable.

Rib fractures. The incidence of rib fractures in child abuse has been variously recorded as $5 \%$ to $27 \%$ (Kleinman 1987b). They are virtually diagnostic of child abuse, being seldom seen as an accidental injury even in 
infants who have been involved in road-traffic accidents. They may occur in severe forms of osteogenesis imperfecta, and are seen, although rarely, in metabolic bone disease and in premature infants. The of ten quoted paper by Feldman and Brewer (1984) stated that even the forces used in cardiopulmonary resuscitation do not result in rib fractures. In 18 years of paediatric radiological practice the author has never encountered a rib fracture caused by cardiac massage and has seen only one fracture from overenthusiastic physiotherapy. The discovery of even one broken rib is therefore highly significant.

In an abused child the fracture may be in any part of the rib, but is more frequent in the posterior or the axillary portions of the bone. The fractures are frequently multiple and bilateral (Fig. 10); they commonly result from a squeezing injury to the chest (Kleinman 1990) when the infant is held by the thorax and shaken. The head oscillates, the thorax is compressed, and the limbs move about with a whiplash movement (Kleinman 1990). Kleinman et al (1992) state that the anteroposterior compression applied during gripping levers the rib over the transverse processes and produces tension in the costovertebral ligaments; the ribs fail mechanically at the head or neck. The neck fractures are most readily detected radiographically or with radionucleides (Kleinman et al 1988). Fractures of the lateral and anterior parts of the ribs may also occur; their incidence depends on the magnitude and direction of the forces applied. The amount of callus is related to the degree of cortical disruption and bleeding. A row of fractures involving the necks and lateral aspects of a number of ribs may result in a flail chest. Lateral and anterior rib fractures may also result from direct trauma, such as kicking, stamping, punching or contact with a hard edge when the infant is forcibly thrown away. Rib fractures are seldom accompanied by external evidence of trauma, even when they are recent, but the callus of healing fractures may be palpable in thin infants.

Recent rib fractures are easily overlooked on radiographs because of overlapping structures and obliquity of the fracture plane relative to the X-ray beam. Even when they are healing, fractures of the rib necks close to the vertebral column may be difficult to see, especially in an underpenetrated radiograph (Fig. 11). Fractures which were invisible when recent (Fig. 12), may only become apparent when they are healing, and it is advisable therefore to repeat the chest film after a week to ten days in suspected cases. Abundant callus may develop around posterior fractures, but a common appearance is a widening of the neck of the rib due to apposition of new bone subperiosteally. Asymmetry of the rib necks between sides and between upper and lower ribs should alert the examiner to the possibility of fractures.

Radionucleide imaging can show posterior rib fractures as areas of increased uptake and more fractures may be visible on these scans than on radiographs. The

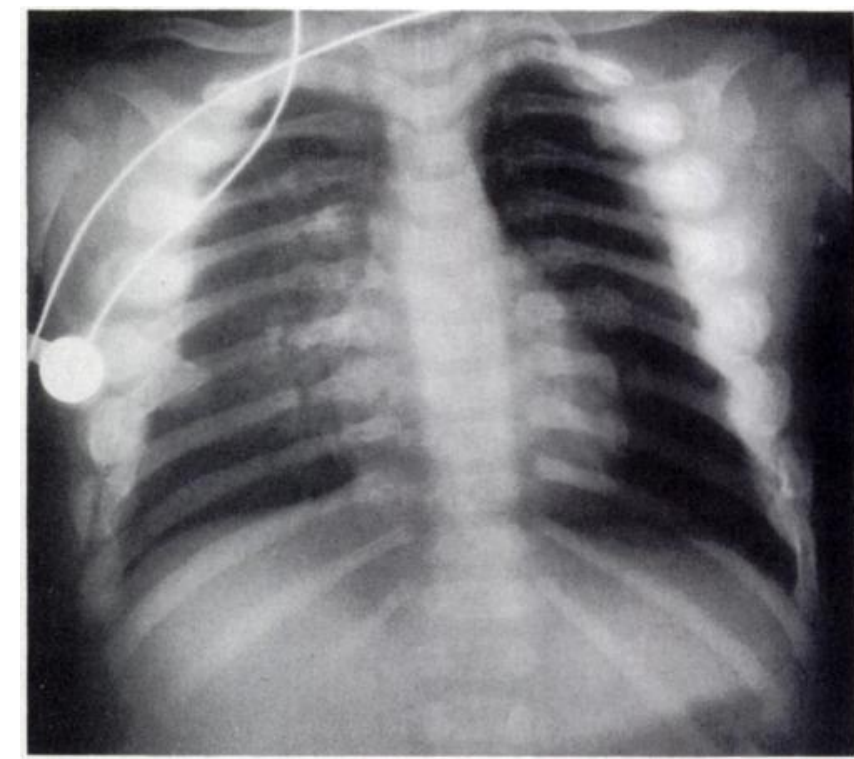

Fig. 10

There are fractures in both axillae and in the necks of several ribs bilaterally. The fractures are of different ages. Intubation was because of the associated head injury.

symmetry of the lesions may cause them to be overlooked by those not familiar with interpreting paediatric radionucleide bone scans. A rib fracture may occasionally resemble a lytic defect when it is seen at the phase of bone resorption and can then be mistaken for some other lesion (Magid and Glass 1990). Rib fractures, like metaphyseal fractures, are most commonly seen in children under one year old (Magid and Glass 1990).

Impaction fractures. A buckle fracture at the diaphysealmetaphyseal junction is another manifestation of abuse and probably occurs at the end of a shaking episode from an impaction force when the child is forcibly thumped down on his leg on a hard surface. In a similar fashion, thumping the child down on its buttocks may result in fracture of a vertebral body (Kleinman 1987c). Spinal fractures and dislocations, however, are usually the result of flexion or lateral flexion injuries (Kleinman 1987c).

\section{DATING OF FRACTURES}

Precise dating of fractures is impossible; one can only define a time band in which it is likely that the fracture occurred. The longer from the time of the injury, the more imprecise is the estimate. In general, the greater the severity of the injury, the longer is the repair process, but in abused children repair may be altered by repeated injury. If the second injury occurs sufficiently long after the first has healed it is usually evident radiographically, but repetitive injuries early in the repair process lead to disproportionate bleeding, and unusually florid signs of repair.

In spite of these problems, there is often a surprising unanimity about the approximate age of a fracture when 


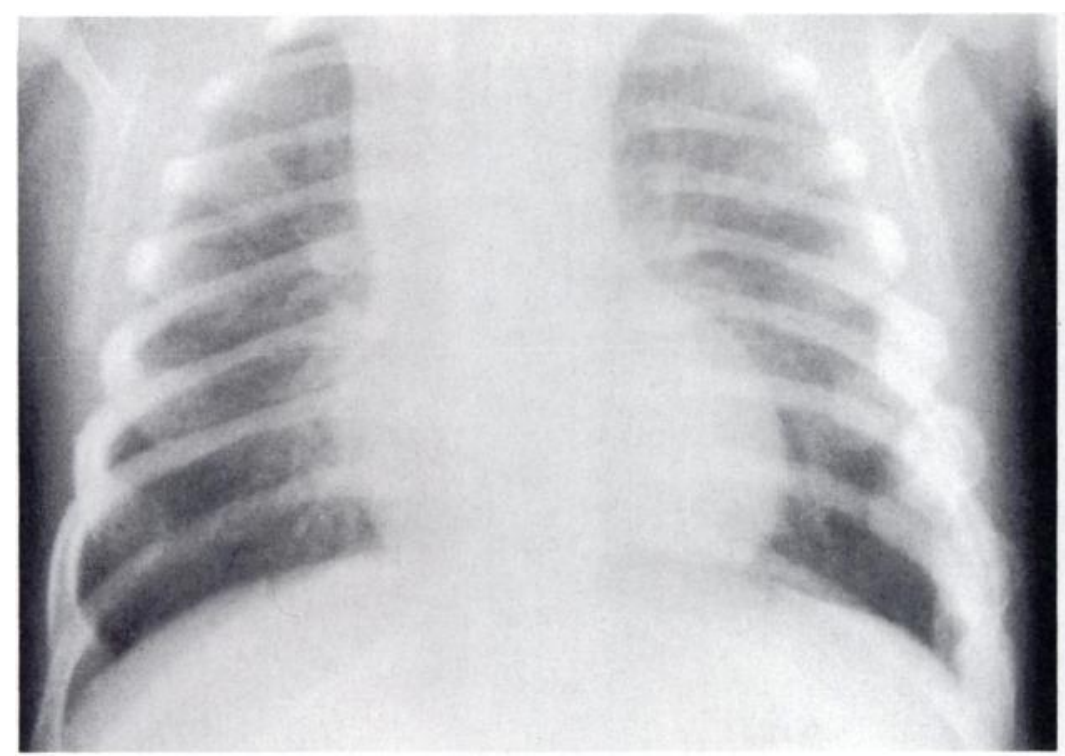

Fig. 11a

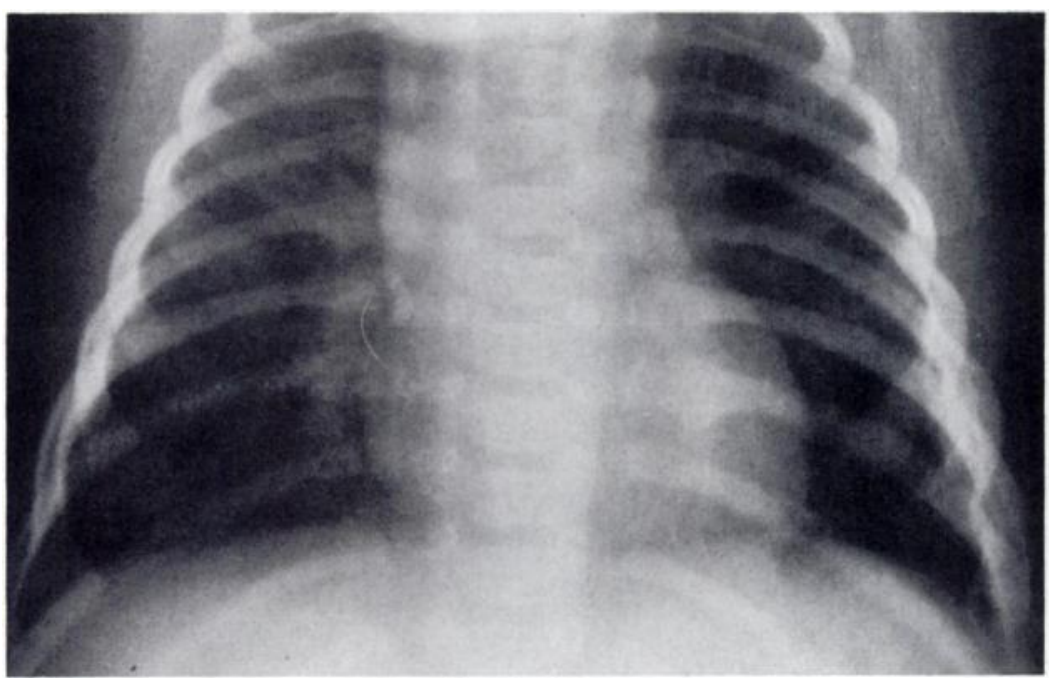

The chest radiograph (a) of a child admitted with a pulmonary infection showed healing rib fractures in the left axilla. The film is underpenetrated and the detail of the rib necks is obscured. A further film seven days later (b) showed several healing posterior rib fractures. Those on the right at 5 and 6 are, in retrospect, visible on the first film.

Fig. $11 \mathrm{~b}$

paediatric radiologists review films independently, although their methods are subjective and depend on the quality of the radiographs. Table IV offers a generally agreed scheme for dating fractures of the long bones but it is not applicable to rib or finger injuries (Duncan, personal communication; O'Connor and Cohen 1987).

It must be emphasised again that some metaphyseal fractures heal without any radiologically detectable periosteal reaction.

\section{DIFFERENTIAL DIAGNOSIS}

In children who present with radiological and clinical evidence of abuse, a differential diagnosis need hardly be considered, but even then great care must be taken to avoid an incorrect diagnosis. The significance of isolated fractures has already been discussed in this review. Most accident departments now have an established policy whereby all children under two years old admitted with
Table IV. Dating of fractures (adapted from O'Connor JF, Cohen J. In: Diagnostic imaging of child abuse. Baltimore: Williams and Wilkins, 1987:112)

\begin{tabular}{lll}
\hline & Time & Peak \\
\hline Soft-tissue resolution & 2 to 10 days & 4 to 10 days \\
Early periosteal new bone & 4 to 21 days & 10 to 14 days \\
Loss of fracture line definition & 10 to 21 days & 14 to 21 days \\
Soft callus & 10 to 21 days & 14 to 21 days \\
Hard callus & 14 to 90 days & 21 to 42 days \\
Remodelling & 3 mths to 2 yrs & \\
\hline
\end{tabular}

an isolated fracture are reviewed by a paediatrician before discharge to ensure that children at risk are not inadvertently discharged to face further injury.

Physiological periostitis and normal metaphyseal variations, both of which can cause confusion, have 


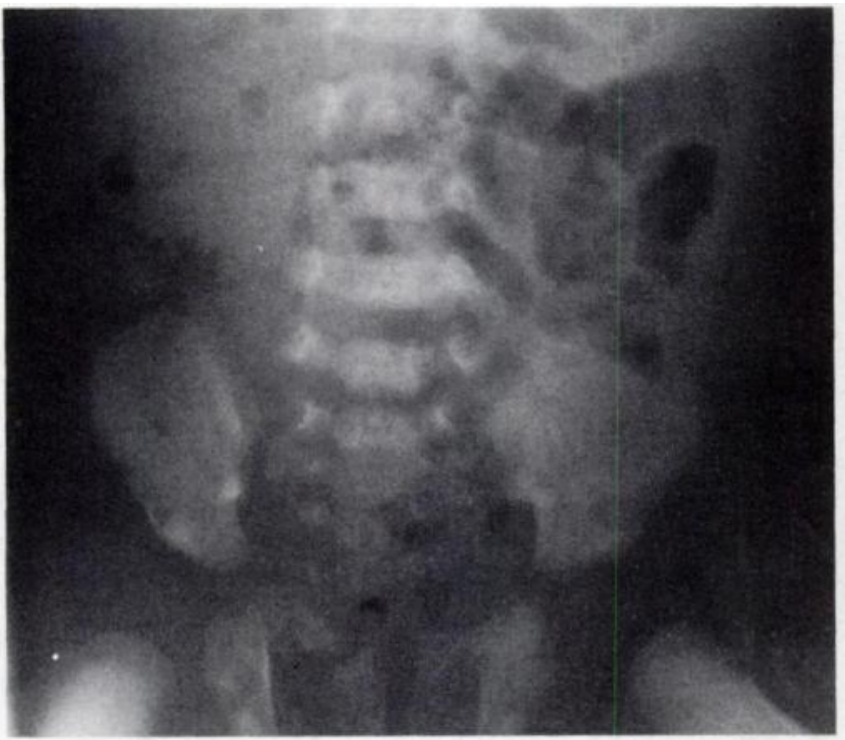

Fig. 12a

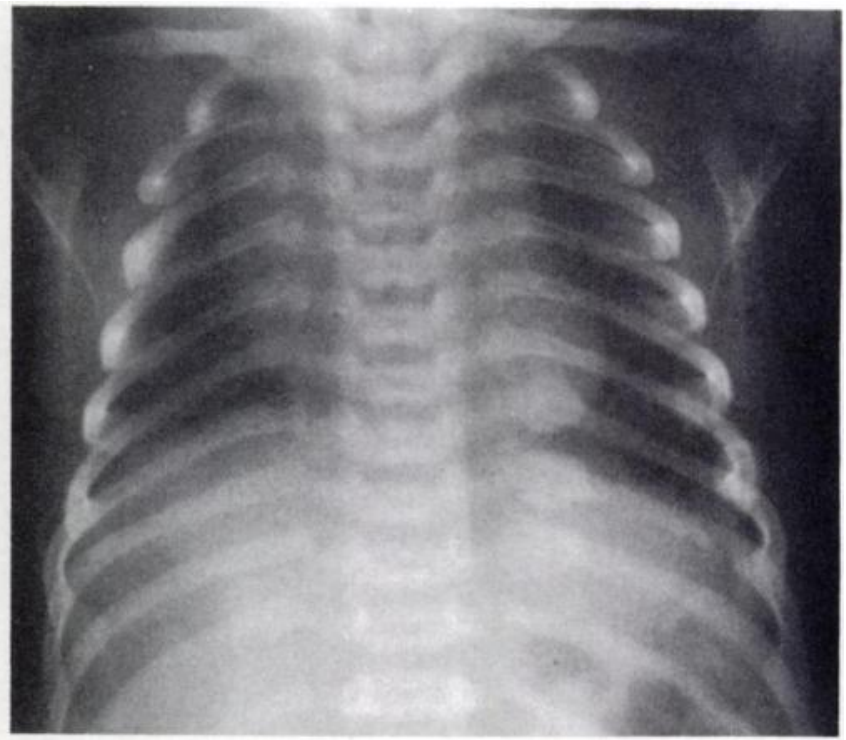

Fig. $12 b$

A six-week-old infant was admitted because of vomiting (a). The chest radiograph was normal. Ten days later a further radiograph (b) showed healing fractures of the necks of the left 7,8 and 9 ribs and of the axillary ends of the 6 and 7 ribs.

Table V. Classification of osteogenesis imperfecta (after Ablin et al 1990)

\begin{tabular}{|c|c|c|c|}
\hline Classification (+ radiological subtypes) & Clinical features & Sclerae & Inheritance \\
\hline $\begin{array}{l}\text { Type I } \\
\text { Subtype A: normal teeth } \\
\text { Subtype B: dentinogenesis imperfecta }\end{array}$ & $\begin{array}{l}\text { Mild to moderately severe osseous fragility } \\
\text { Normal or near-normal stature } \\
\text { Presenile hearing loss or impairment (or family } \\
\text { history) } \\
\text { Most common type }\end{array}$ & Blue & Autosomal dominant \\
\hline \multicolumn{4}{|l|}{ Type II } \\
\hline $\begin{array}{l}\text { Subtype A : broad, crumpled, long bones } \\
\text { broad ribs with continuous beading }\end{array}$ & $\begin{array}{l}\text { Lethal in fetal or perinatal period } \\
\text { Very severe osseous fragility }\end{array}$ & Blue & $\begin{array}{l}\text { Autosomal dominant - } \\
\text { new mutation or } \\
\text { autosomal recessive } \\
\text { (rare) }\end{array}$ \\
\hline $\begin{array}{c}\text { Subtype B: broad, crumpled, long bones } \\
\text { discontinuous or no beading of ribs } \\
\text { Subtype C : thin, fractured, long bones } \\
\text { thin, beaded ribs }\end{array}$ & Intrauterine growth retardation & & \\
\hline Type III & $\begin{array}{l}\text { Moderate to severe osseous fragility } \\
\text { Progressive deformity of long bones and spine } \\
\text { Short stature and severe growth retardation } \\
\text { Deafness less frequent than type I }\end{array}$ & $\begin{array}{l}\text { Normal or pale } \\
\text { blue or grey in } \\
\text { infancy } \\
\text { becoming normal }\end{array}$ & $\begin{array}{l}\text { Autosomal dominant - } \\
\text { new mutation or } \\
\text { autosomal recessive } \\
\text { (rare) }\end{array}$ \\
\hline $\begin{array}{l}\text { Type IV } \\
\text { Subtype A: normal teeth } \\
\text { Subtype B: dentinogenesis imperfecta }\end{array}$ & $\begin{array}{l}\text { Mild to moderately severe osseous fragility } \\
\text { Variable deformity of long bones and spine } \\
\text { Deafness less frequent than in type I }\end{array}$ & Normal & Autosomal dominant \\
\hline
\end{tabular}

already been discussed. Radiologists and orthopaedic surgeons must be familiar with these to avoid an incorrect diagnosis of abuse.

Metaphyseal fractures may occur during a difficult breech delivery or during caesarean section. Such fractures are identical to those caused by abuse but careful dating of the fractures should avoid confusion.

The main differential diagnoses are metabolic bone disease and osteogenesis imperfecta. Rickets and scurvy are easily eliminated by biochemical testing and their radiological features are so typical that they should not lead to misdiagnosis. Copper deficiency as a differential diagnosis has been thoroughly discussed (Carty 1988;
Shaw 1988), but deficiency of sufficient severity to lead to lesions that might be confused with child abuse is very rare (Shaw 1988).

The major differential diagnosis, therefore, is between child abuse and one of the forms of osteogenesis imperfecta. Ablin et al (1990) have detailed the problem and reviewed the evidence. The classification of osteogenesis imperfecta now used is given in Table V. Types II and III should not cause diagnostic difficulty as the bone disease is usually severe. In the mild forms of type I accidental fractures do not usually occur before the child starts to walk while those due to child abuse are more frequent under one year. In the more severe forms of type 
I osteogenesis imperfecta there is obvious osteoporosis (Ablin et al 1990) and the children have wormian bones and distinctly blue sclerae (Ablin et al 1990). Their fractures usually occur in the diaphyses and are unlike the corner metaphyseal fractures of abuse, although metaphyseal fractures are sometimes found (Astley 1979). Type IV is a rare form; only a few documented families and sporadic cases have been reported (Ablin et al 1990). Taitz (1987) estimated that in a child under one year of age, with no family history, and normal skull and teeth, the chance that fractures are related to type IV osteogenesis imperfecta is less than three in a million. Many of the reports of this type have come from one author (Paterson, McAllion and Shaw 1987) but the validity of his work has been questioned (Ablin et al 1990). In practice, provided that care is taken to survey the evidence critically and remembering that blue sclerae are normal in infants up to four months old (Ablin et al 1990), diagnostic confusion should not occur. Metaphyseal and rib fractures are not features of mild osteogenesis imperfecta, although they do occur in the severe forms, when other evidence of brittle bones is unequivocally present (Astley 1979). Subdural haematoma and skull fracture are not features of osteogenesis imperfecta.

The differential diagnosis between abuse and osteogenesis imperfecta often requires collaboration between the radiologist, the orthopaedic surgeon and the paediatrician. Fibroblast culture to identify collagen defects may one day provide the solution, but until then problem cases can only be resolved by the passage of time as the typical bone changes of osteogenesis imperfecta evolve. Overdiagnosis of child abuse is a tragedy but an incorrect diagnosis of osteogenesis imperfecta may put a child's life at risk. Osteogenesis imperfecta in all its forms is an uncommon disease; child abuse, sadly, is not.

No benefits in any form have been received or will be received from a commercial party related directly or indirectly to the subject of this article.

\section{REFERENCES}

Ablin DS, Greenspan A, Reinhart M, Grix A. Differentiation of child abuse from osteogenesis imperfecta. Am J Roentgenol 1990; $154: 1035-46$

Akbarnia B, Torg JS, Kirkpatrick J, Sussman S. Manifestations of the battered-child syndrome. J Bone Joint Surg [Am] 1974; 56-A: 1159-66.

Anderson WA. The significance of femoral fractures in children. Ann Emerg Med 1982; $11: 174-7$.

Astley R. Metaphyseal fractures in osteogenesis imperfecta. Br J Radiol 1979:52:441-3.

Beals RK, Tufts E. Fractured femur in infancy: the role of child abuse. J Pediatr Orthop 1983; 3:583-6.

Caffey J. Multiple fractures in the long bones of infants suffering from chronic subdural hematoma. Am J Roentgenol 1946; 56:163-73.

Caffey $\mathbf{~ J}$. Some traumatic lesions in growing bones other than fractures and dislocations: clinical and radiological features. $B r J$ Radiol 1957; 30:225-38.

Carty H. Brittle or battered. Arch Dis Child 1988; 63:350-2.

Chapman S. Radiological aspects of non-accidental injury. $J R$ Soc Med $1990 ; 83: 67-71$.
Ebbin AJ, Gollub MH, Stein AM, Wilson MG. Battered child syndrome at the Los Angeles County General Hospital. Am J Dis Child 1969; 118:660-7.

Ellerstein NS, Norris KJ. Value of radiologic skeletal survey in assessment of abused children. Pediatrics 1984; 74:1075-8.

Feldman KW, Brewer DK. Child abuse, cardiopulmonary resuscitation and rib fractures. Pediatrics $1984 ; 73: 339-42$.

Griffiths DL, Moynihan FJ. Multiple epiphysial injuries in babies ('battered baby' syndrome). Br Med J 1963;2:1558-61.

Herndon WA. Child abuse in a military population. $J$ Pediatr Orthop 1983; 3:73-6.

Kempe CH, Silverman FN, Steele BF, Droegemuller W, Silver HK. The battered-child syndrome. J Amer Med Assoc 1962;181:17-24.

King J, Diefendorf D, Apthorp J, Negrete VF, Carlson M. Analysis of 429 fractures in 189 battered children. J Pediatr Orthop 1988; 8:585-9.

Kleinman PK. Skeletal trauma: general considerations. In: Kleinman PK, ed. Diagnostic imaging in child abuse. Baltimore, etc: Williams \& Wilkins, 1987a:10

Kleinman PK. Bony thoracic trauma. In: Kleinman PK, ed. Diagnostic imaging in child abuse. Baltimore, etc: Williams \& Wilkins, $1987 b: 67$.

Kleinman PK. Spinal trauma. In: Kleinman PK, ed. Diagnostic imaging in child abuse. Baltimore, etc: Williams \& Wilkins, 1987c:91-102.

Kleinman PK. Diagnostic imaging in infant abuse. Am $J$ Roentgenol $1990 ; 155: 703-12$.

Kleinman PK, Marks SC, Blackbourne B. The metaphyseal lesion in abused infants: a radiologic-histopathologic study. Am J Roentgenol $1986 ; 146: 895-905$.

Kleinman PK, Marks SC, Adams VI, Blackbourne BD. Factors affecting visualization of posterior rib fractures in abused infants. Am J Roentgenol 1988: $150: 635-8$.

Kleinman PK, Marks SC Jr, Spevak MR, Belanger PL, Richmond JM. Extension of growth-plate cartilage into the metaphysis: a sign of healing fracture in abused infants. Am $J$ Roentgenol 1991a; 156:775-9.

Kleinman PK, Belanger PL, Karellas A, Spevak MR. Normal metaphyseal radiologic variants not to be confused with findings of infant abuse. Am J Roentgenol 1991 b; 156:781-3.

Kleinman PK, Marks SC, Spevak MR, Richmond JM. Fractures of the rib head in abused infants. Radiology 1992; 185:119-23.

Kogutt MS, Swischuk LE, Fagan CJ. Patterns of injury and significance of uncommon fractures in the battered child syndrome. Am J Roentgenol 1974: $121: 143-9$.

Loder RT, Bookout C. Fracture patterns in battered children. J Orthop Trauma 1991; 5:428-33.

Magid N, Glass T. A 'hole in a rib' as a sign of child abuse. Pediatr Radiol 1990; 20:334-6.

Merten DF, Radkowski MA, Leonidas JC. The abused child: a radiological reappraisal. Radiology $1983 ; 146: 377-81$.

O'Connor JF, Cohen J. Dating fractures. In: Kleinman PK, ed. Diagnostic imaging of child abuse. Baltimore, etc: WIlliams \& Wilkins, 1987:103-13.

Paterson CR, McAllion SJ, Shaw JW. Clinical and radiological features of osteogenesis imperfecta type IVA. Acta Paediatr Scand 1987; $76: 548-52$.

Shaw JC. Copper deficiency and non-accidental injury. Arch Dis Child 1988: 63:448-55.

Silverman FN. Unrecognized trauma in infants, the battered child syndrome and the syndrome of Ambroise Tardieu. Radiology 1972: 104:337-53.

Sty JR, Starshak RJ. The role of bone scintigraphy in the evaluation of the suspected abused child. Radiology 1983; 146:369-75.

Taitz LS. Child abuse and osteogenesis imperfecta. Br Med J 1987; 295:1082-3.

Thomas SA, Rosenfield NS, Leventhal JM, Markowitz RI. Long-bone fractures in young children : distinguishing accidental injuries from child abuse. Pediatrics 1991; 88:471-6.

Worlock P, Stower M, Barbor P. Patterns of fractures in accidental and non-accidental injury in children : a comparative study. Br Med $J$ $1986 ; 293: 100-2$ 